\title{
HIDROLOGIA DO SACO DA FAZENDA, ITAJAÍ, SC
}

\author{
SCHETTINI, C.A.F. \\ Laboratório de Oceanografia Física - LOF. \\ Centro de Ciências Tecnológicas da Terra e do Mar - CTTMar \\ Universidade do Vale do Itajaí - UNIVALI. CxP. 360, Itajaí, SC, 88302-202, \\ carlos.schettini@pq.cnpq.br (Bolsa CNPq - 306217/2007-4)
}

\begin{abstract}
Schettini, C.A.F. 2008. Hydrology of Saco da Fazenda, Itajaí, SC.Braz. J. Aquat. Sci. Technol. 12(1):49-58. ISSN 1808-7035. The Saco da Fazenda (SF) is a semi-enclosed coastal water body artificially made and inserted in the urban scenario of Itajaí city. The SF was created from the enterprise of retification of the access channel to the Port of Itajaí. The last curvature of the lower estuary was isolated from the main channel, and then creating the SF. Nowadays it is a depositional basin for the sediments from the Itajaí-Açu River and from small streams which drains the Itajaí City downtown. These small streams flow to the SF with no treatment at all, and, consequently, the water quality is low. Applying basic morphological data and hydrographic data from the SF and the lower Itajaí-Açu estuary, it was estimated the flushing time of the SF and the exchange level between the SF and the lower estuary. The flushing time is basically function of the tidal prism exchange, and the half-live was estimated as of the order of 'few days', or specifically 0,8 to 2,6 days varying the tidal height of neap and spring tide, respectivelly. The salinity of the SF the same of the upper layer of the lower estuary, and varies inversely and non-linearly related to the Itajaí-Açu river discharge, indicating higher level of eschange between them.
\end{abstract}

Keywords: coastal lagoon; residence time; salinity.

\section{INTRODUÇÃO}

O Saco da Fazenda (SF) é um corpo de água costeiro restrito inserido no cenário urbano de Itajaí (Figura 1). Este ambiente foi criado artificalmente pela intervenção de obras de engenharia no baixo estuário do rio Itajaí-Açu. Aárea que ocupa atualmente consistia de um último meandro do estuário que margeava a orla atual e era orientado para o norte pelo morro do Atalaia, havendo na outra margem um pontal arenoso que se prolongava a partir da Praia de Navegantes. $O$ crescimento da atividade portuária em Itajaí gerou a necessidade de estabelecer o porto organizado com infra-estrutura adequada. Estudos iniciais para a implantação do porto consideraram três locais, sendo a Praia de Cabeçudas, o último meandro do estuário (o atual SF), e onde é atualmente. Com o projeto estabelecido, surgiu também a necessidade de tornar o acesso do ao porto seguro, implicando nas obras de construção dos molhes de Itajaí. As obras do canal de acesso envolveram além da construção dos molhes para estabilização da desembocadura, a construção de espigões e guias correntes em ambas as margens do baixo estuário do rio Itajaí-Açú.

A Figura 2 apresenta a fisiografia da região da desembocadura do estuário do rio Itajaí-Acú no final do século XIX, antes do início de qualquer obra de retificação, e a situação em 1982, quando todas as obras de retificação estavam concluídas. A partir de 1982 até o presente não houve novas obras a não ser de manutenção das estruturas já existents e de aprofundamento do canal. O SF foi formado durante as obras de retificação do canal de acesso ao Porto de Itajaí (Fig. 2). O seu isolamento do baixo estuário ocorreu em diferentes fases. Um primeiro guia corrente foi inicialmente construído com orientação S-SE, que em conjunto com um espigão partindo da margem sul num alinhamento aproximadamente ortogonal a margem, mantendo uma abertura para circulação das águas. Posteriormente foi construído um novo guia corrente com orientação E-SE, que se prolongava até o promontório do Atalaia e dava início ao molhe sul. Foram mantidas duas aberturas neste último guia corrente: uma menor mais para oeste e próximo do início da curvatura do SF, e outra maior próximo da outra extremidade (Fig. 1). Atualmente a superfície do SF é de 63 hectares, com formato aproximadamente triangular. O eixo paralelo ao estuário do rio Itajaí-Açú apresenta cerca de 1,3 km, e a largura máxima é da ordem de $0,7 \mathrm{~km}$. Não existe informações sobre a batimetria após a dragagem realizada entre 2000 e 2003, porém, considerando o projeto de dragagem, a profundidade média é cerca de 1,5 m.

O SF integra o sistema estuarino do rio ItajaíAçú, o qual inclui também o baixo curso do rio ItajaíMirim, o canal do Itajaí-Mirim e braço morto. O estuário 


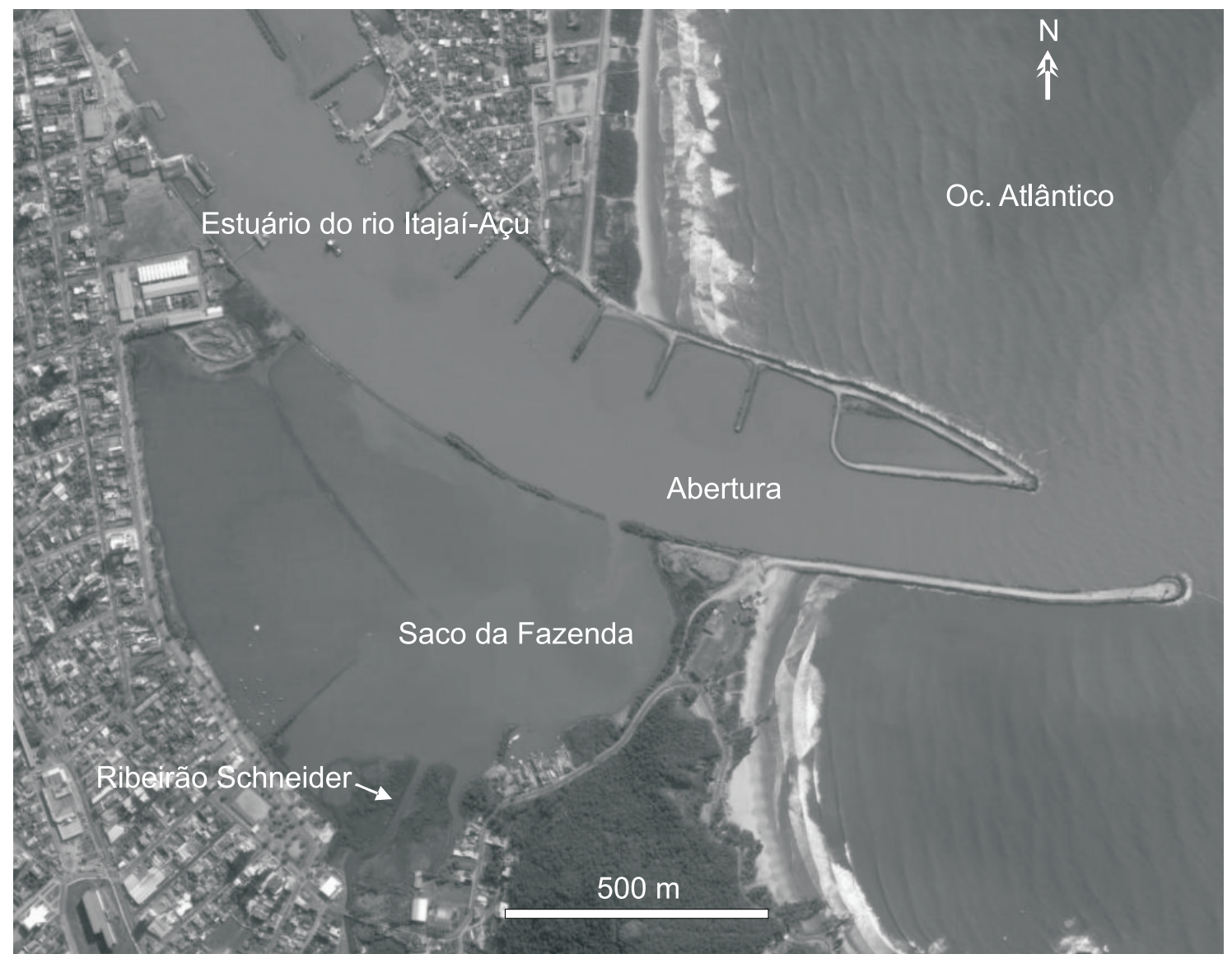

Figura 1 - Imagem de satélite recente apresentando a situação atual do Saco da Fazenda. Imagem obtida a partir do Google Earth.

do rio Itajaí-Açú é um estuário altamente estratificado, e os processos de transporte e de mistura são controlados primeiramente pela vazão do rio Itajaí-Açú quando esta se apresente elevada, ou pelos efeitos oscilatórios periódicos das marés astronômicas durante os períodos de baixa vazão (Schettini, 2002). O SF, por outro lado, é um sistema anexo ao estuário, sendo que os processos que controlam sua hidrodinâmica diferem dos observados no estuário. Isto é primeiramente compreendido quando distinguimos em termos fisiográficos os dois sistemas. O estuário do rio ItajaíAçú é estreito ( $200 \mathrm{~m}$ ), comprido ( $70 \mathrm{~km}$ ) e profundo ( $8 \mathrm{~m})$, sendo sua morfologia o resultado do ajuste hidráulico do regime fluvial. O saco, por outro lado, é largo, não podendo ser claramente distinguido um eixo longitudinal $(\sim 1 \times 1 \mathrm{~km})$, e raso $(\sim 1,5 \mathrm{~m})$. O estuário é classificado em termos fisiongráficos com um estuário de frente deltaica, segundo o modelo de classificação de Fairbridge (1980). O SF pode é classificado como um estuário de barra, mais comumente denominado de lagoa costeira. Uma descrição detalhada dos aspectos físicos regionais e especificamente do estuário do Rio Itajaí-Açu é apresentado em Schettini (2002). Em termos gerais, o regime é de micro-marés misto com predominância semi-diurna, com altura variando entre 0,4 e 1,2 m entre períodos de quadratura e sizígia, respectivamente. A vazão média histórica é da ordem de $350 \mathrm{~m}^{3} . \mathrm{s}^{-1}$, apresentando-se bastante variável no tempo, sem uma distinção sazonal.

\section{Lagoas Costeiras}

Lagoas costeiras constituem um ambiente costeiro comum ao redor de todo o globo (Kjerfve, 1994). Lagoas costeiras são áreas continentais continuamente inundadas por águas marinhas ou doces, aproximadamente orientadas paralelamente à linha de costa, separadas do oceano por uma barreira arenosa, e conectadas a ele por canais (Phleger, 1981), ao menos em regime intermitente (Lankford, 1977; Moore \& Slinn, 1984; Kjerfve, 1986; Kjerfve \& Magill, 1989). Estes ambientes são mais comuns em regiões que apresentam ampla plataforma continental conjuntamente com uma extensa planície costeira (Emery, 1967; Nichols \& Biggs, 1985), com baixa altura de maré, regime de ondas bastante energético e um grande suprimento de material sedimentar arenoso (Lankford, 1977; Kjerfve, 1986).

Em relação aos processos de mistura de águas, lagoas costeiras podem ser classificadas como 


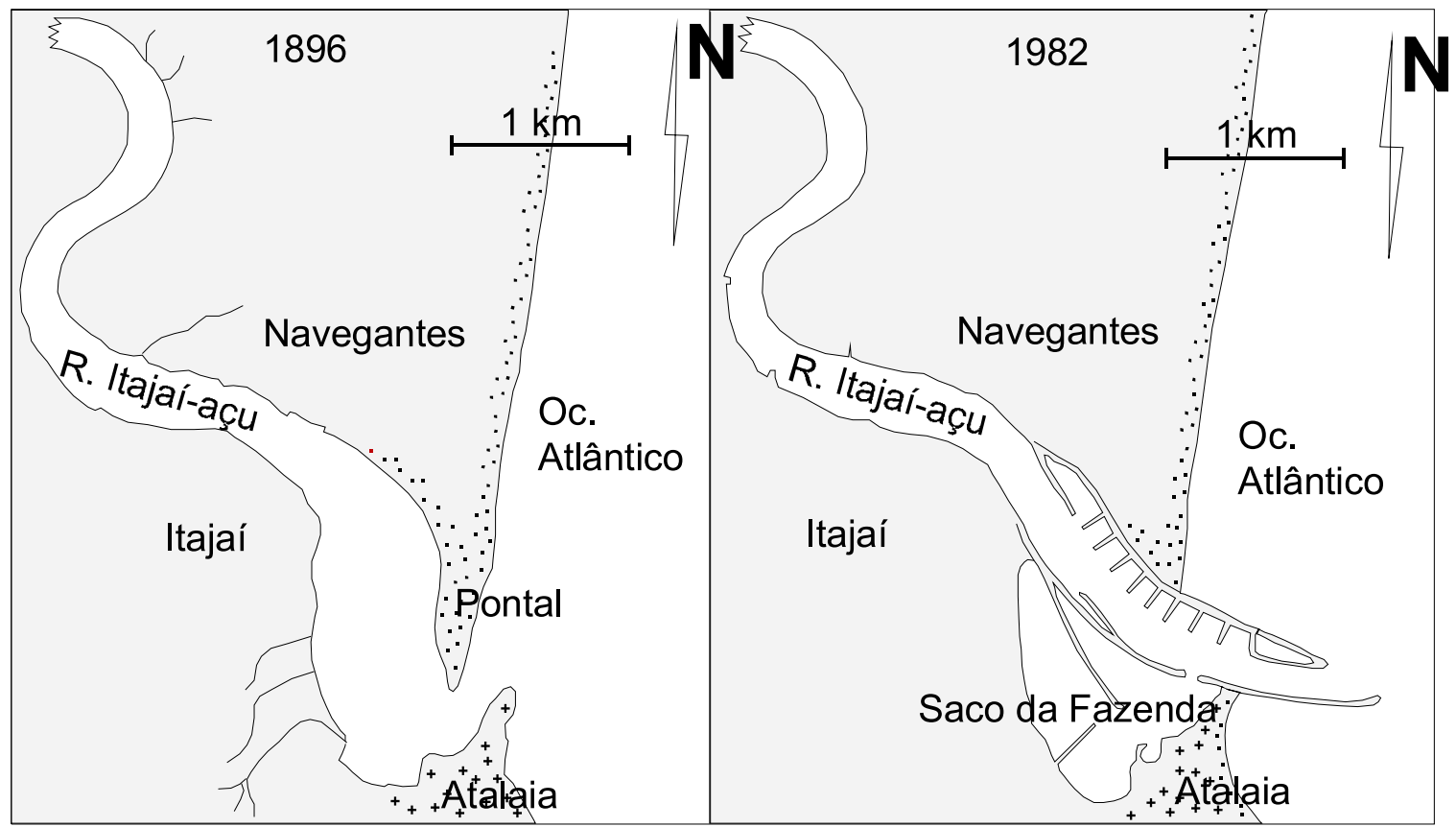

Figura 2 - Situação do baixo estuário do rio Itajaí-Açú em 1896, antes das retificações, e em 1982 (modificado de Vargas, 1983).

estuários do tipo verticalmente homogêneo de acordo com a classificação de balanço de sal proposta por Cameron \& Pritchard (1963). Em relação à estratificação da salinidade e da velocidade de corrente na coluna de água, são classificadas como $1 \mathrm{a}$ e $1 \mathrm{~b}$ de acordo com a classificação dinâmica proposta por Hansen \& Rattray (1966). Estas classificações demonstram a predominância de processos de mistura horizontal dominados por macro-difusão molecular (Zimmerman, 1981), embora no canal de ligação com o oceano possa haver dominância de processos advectivos (Kjerfve \& Knoppers, 1991).

Embora as lagoas costeiras ocupem $13 \%$ das áreas litorâneas do mundo (Barnes, 1980), o conhecimento dos processos atuantes nestes ambientes ainda é muito esparso, e muitos fenômenos têm suas explicações apenas no campo conjectural. Em função das trocas entre a lagoa e o oceano adjacente, como resposta da interação entre a geomorfologia e processos oceanográficos, as lagoas costeiras podem ser classificadas como (1) sufocadas, (2) restritas, ou (3) vazadas (Kjerfve, 1986; Fig. 3).

Lagoas costeiras podem ter suas características naturais alteradas tanto devido à causas naturais (ex. fechamento periódico da barra), como antropogênicas (ex. esgotos domésticos) (Smith, 1988; Merino et al. 1990; Knoppers et al. 1991; Carmouze, 1992), sendo que as lagoas do tipo sufocada são particularmente mais suscetíveis à deterioração da qualidade da água, em resposta às baixas razões de troca com o oceano e prolongado tempo de renovação de suas águas. Os processos dinâmicos que ocorrem no canal de ligação com o oceano nestes tipos de sistemas apresentam grande importância para a qualidade da água (Kjerfve \& Knoppers, 1991), possibilitando manter condições de águas completamente doces até continuamente hipersalinas (Kjerfve, 1986; Kjerfve \& Magill, 1989; Knoppers et al. 1991).

O SF é uma lagoa costeira criada pelas alterações fisiográficas do estuário do rio Itajaí-Açu, e apresenta um elevado grau de troca com o baixo estuário. Isto é comprovado pela variação do nível da água dentro do SF que segue o padrão do estuário, e desta forma pode ser considerado como uma lagoa costeira do tipo vazada. O fluxo de água entre a lagoa e o estuário ocorre através da abertura na porção leste do guia corrente, e também através do guia corrente, uma vez que é uma estrutura de blocos de rochas permeável. O problema da questão da qualidade da água do SF está diretamente relacionado com a taxa de renovação de água do saco, além da carga lançada, obviamente. O aporte fluvial direto para o SF se dá através de alguns pequenos tributários ao longo de sua margem sul, sendo que o ribeirão Schneider é o de maior significância em termos volumétricos (Fig. 1). 0 objetivo do presente trabalho é estabelecer relações hidrológicas para o SF a partir da análise de escala de variáveis geomorfológicas e hidrográficas.

\section{MATERIAL E MÉTODOS}

Uma grande dificuldade em estudos em cursos de água de pequenas dimensões é a indisponibilidade 


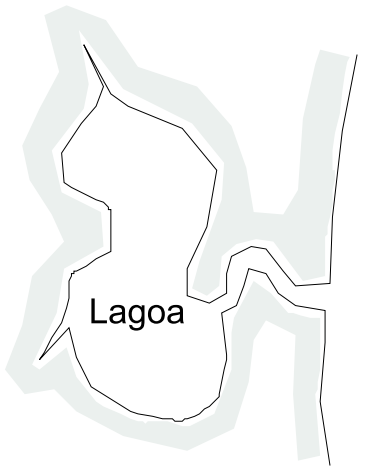

SUFOCADA

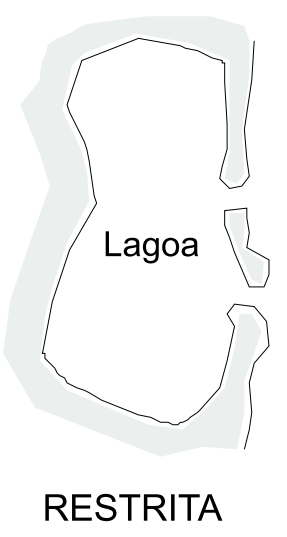

VAZADA

Figura 3 - Representação esquemática de lagoas costeiras segundo Kjerfve (1986).

de dados de descarga. Para estabelecer um valor realista de descarga fluvial direta para o SF foi aplicado o balanço de massa através da equação hidrológica (Eq. 1), onde o excedente hídrico do balanço entre precipitação e evapotranspiração é convertido em vazão poderada pela área da bacia.

O tempo de renovação das águas do saco foi estimado pela razão entre o volume pela vazão. Porém, o tempo foi considerado como tempo de meia vida, ou seja, o tempo necessário para renovar $50 \%$ do volume (Pritchard, 1961). Isto é uma estimativa mais conservativa considerando que o saco apresenta trocas basicamente através de uma abertura única por onde a água entra e sai.

A inter-relação entre o saco e o baixo estuário foi avaliada baseando-se na salinidade média de ambos os sistemas. A salinidade do baixo estuário foi obtida a partir do monitoramento ambiental das dragagens do Porto de Itajaí para os anos de 1998 e 1999. Estes dados foram coletados semanalmente ao longo de todo o estuário utilizando uma sonda de registro contínuo de condutividade, temperatura e pressão da marca Saiv $\mathrm{A} / \mathrm{S}$, sendo realizados perfis verticais ao longo de toda a coluna de água. Dados de salinidade para o saco foram obtidos a partir do monitoramento ambiental da dragagem do Saco da Fazenda no período de 2000 a 2003. Os dados foram obtidos com o emprego de uma sonda multi-parâmetros Horiba, sendo obtidos para 0,5 $\mathrm{m}$ de profundidade, mensalmente. Estes mesmos dados foram utilizados para avaliar a variabilidade temporal da salinidade do saco, e a obtenção de um modelo empírico da salinidade como função da vazão do rio Itajaí-Açu para a estação fluviométrica de Indaial. Esta estação monitora a vazão do rio diariamente, estando distante cerca de $90 \mathrm{~km}$ da desembocadura, e é a estação mais a jusante que não apresenta efeitos da maré. O modelo de ajuste foi gerado utilizando a ferramenta 'cftool' em ambiente Matlab.

\section{RESULTADOS E DISCUSSÃO}

\section{Descarga do Ribeirão Schneider}

A vazão de um curso de água é a resposta direta do balanço hidrológico da sua bacia hidrográfica. A taxa de armazenamento de água $Q$ em uma bacia ao longo do tempo té diretamente relacionada com os fluxos de entrada e saída de água. Em termos de processos de curto período, o fluxo de entrada de água em uma bacia será estritamente em função da taxa de precipitação $P$, enquanto que o fluxo de saída será dividido entre a taxa de evapotranspiração $E T$ e a vazão fluvial $V_{f}$ Este balanço é descrito através da equação hidrológica

$$
\frac{d Q}{d t}=P-E T-V_{f}
$$

Para eventos de precipitação na bacia em escala de tempo curta (por exempo, de horas a dias), o termo do lado esquerdo da igualdade torna-se positivo pelo aumento da quantidade de água armazenada na bacia, e será proporcional ao balanço direto entre a precipitação e a vazão, podendo ser desprezada a evapotranspiração. Alternativamente, se considerarmos um período de tempo longo o suficiente, o termo do lado esquerdo da igualdade tende a zero, uma vez que o volume de água médio na bacia muda pouco em prazos longos de tempo. Em termos climatológicos, $\mathrm{dQ} / \mathrm{dt}=0$, e uma estimativa razoável da vazão fluvial média de longo período torna-se 


$$
V_{f}=P-E T
$$

Considerando que a vazão corresponde ao transporte de volume por tempo, dado $\mathrm{em}^{3} . \mathrm{s}^{-1}$, e que tanto a taxa de precipitação quanto a evapotranspiração são quantificadas em termos de distância pelo tempo, ou velocidade de entrada ou saída de água da bacia, em mm.ano ${ }^{-1}$, os valores convertidos para metros devem ser integrados para a área da bacia $\mathrm{em}^{2} \mathrm{e}$ derivados para unidade de tempo em segundos. Dada a área da bacia hidrográfica da ordem de $5 \mathrm{~km}^{2}$ (Rörig et al., 2006), e as taxas de precipitação e evapotranspiração para Itajaí de 1495 e 915 mm.ano-1 (Gaplan, 1986), respectivamente, obteremos um valor para a vazão média anual da ordem de $0,1 \mathrm{~m}^{3} \cdot \mathrm{s}^{-1}$. Contudo, existem outros pequenos cursos de água que fluem para o Saco da Fazenda. Estes outros cursos de água são de dimensões menores, e numa estimativa razoável talvez dobrem a área de drenagem. Assim, a vazão fluvial total para o Saco da Fazenda pode ser escalada da ordem de $0,2 \mathrm{~m}^{3} \cdot \mathrm{s}^{-1}$.

Um aspecto importante a ser considerado quanto ao comportamento hidrológico de pequenos cursos de água em regiões urbanas é o efeito de impermeabilização do solo decorrente da pavimentação e construções. A razão de escoamento, dada pela razão entre o volume precipitado e o volume que escoa superficialmente, aumenta, pois o volume de água que infiltraria nestas áreas passa a compor parte do escoamento superficial. As conseqüências diretas são: (i) a redução do tempo de concentração, (ii) a elevação do pico de cheia, e (iii) diminuição do escoamento basal. Tempo de concentração é o tempo decorrido do início da precipitação até o pico de vazão em uma seção de controle. Pico de cheia é o nível máximo atingido na seção de controle após o início da precipitação. E escoamento basal é o escoamento que perdura no curso de água quando não está chovendo, alimentado pelo escoamento subterrâneo. Ou seja, mesmo que em termos médios a vazão estimada da drenagem do saco seja da ordem de $0,2 \mathrm{~m}^{3} . \mathrm{s}^{-1}$, ela é inferior a este valor na maior parte do tempo, e se eleva drasticamente durante eventos de precipitação da bacia. Por exemplo, um evento de precipitação intensa da ordem de $50 \mathrm{~mm}$ em 3 horas, possível de ocorrer durante uma chuva de verão, poderia produzir uma vazão da ordem de 2 a 4 $\mathrm{m}^{3} \cdot \mathrm{s}^{-1}$.

Além do aspecto de balanço de massa de água para o saco, outro elemento importante de nota é quanto à qualidade da água aportada pelos pequenos tributários do saco. Rörig et al. (2006) apresentam uma análise aprofundada do estado da qualidade ambiental da bacia hidrográfica do ribeirão Schneider. Neste trabalho onde foram levantadas diversas variáveis ambientais, constata-se o elevado estado de degradação ambiental na bacia, o que somado a inexistência de um sistema de captação e tratamento de esgotos torna estes cursos de água como cloacas urbanas. Mais dos que tributários para o Saco da Fazenda, estes pequenos cursos de água atualmente são fontes poluidoras, segundo Rörig et al. (2006).

\section{Estimativa do Tempo de Renovação}

Uma observação empírica sobre o SF permite a um observador alheio interpretar que a qualidade da água é no mínimo razoável, uma vez que aves, peixes e crustáceos são abundantes neste ambiente. Isto é um contraponto em relação ao fato de que os pequenos cursos de água que ali desembocam trazem cargas elevadas de poluentes (Rörig et al., 2006). O que se passa é que a água deste ambiente é continuamente trocada com o baixo estuário, e este, por sua vez, com o oceano adjacente. Porém, mais importante do que saber que a água está sendo trocada, é saber em que escala de tempo que isto ocorre. Sendo tipologicamente uma lagoa vazada, o tempo de renovação da água no SF é relativaemente curto.

O tempo de renovação das águas de um sistema costeiro semi-fechado representa o tempo necessário para que toda a água contida neste sistema seja trocada. Porém o tempo de residência tenderá ao infinito se alguma área do sistema permanecer submersa permanentemente. Uma alternativa para se estimar a renovação de águas em lagoas costeiras é a adoção do conceito de meia vida, ou o tempo necessário para renovar metade da água do sistema (Knoppers et al. 1991). Pressupondo que a renovação do volume $V$ através do tempo tocorra a uma taxa constante $k$

$$
\frac{d V}{d t}=-k V
$$

(Pritchard, 1961), esta pode ser integrada a partir de um instante inicial, com o volume $V_{0}$, até um lapso de tempo $T_{50 \%}$, quando o volume ainda será o mesmo, porém metade será constituída pela parcela de água inicial, e metade será constituído de água nova, ou $\mathrm{V}_{\text {novo }}$ ' $\mathrm{V}=0,5$. Integrando, teremos

$$
T_{50 \%}=\frac{0,69}{k}
$$

(Knoppers et al. 1991). A taxa de renovação k depende de diversos fatores, como a vazão fluvial, troca devido às marés, grau de mistura de águas, geometria do sistema, etc. Para o caso do SF, a vazão fluvial direta da sua bacia de drenagem apresenta um volume de 
água muito pequeno quando comparado com o volume de água trocado periodicamente com o estuário adjacente em função da maré. A razão de fluxo $R_{F}$ para pode ser calculada por

$$
R_{F}=\frac{\int_{0}^{12,4} V_{f}}{P_{M}}
$$

onde o numerador é a vazão fluvial integrada por um ciclo completo de maré, e $P_{M}$ é o prisma de maré (Dyer, 1997). O prisma de maré representa o volume de água potencialmente trocado a cada ciclo de maré, calculado pelo produto da altura da maré, $h$, pela área da superfície do saco $A, P_{M}=A h$. A área da superfície do Saco da Fazenda é cerca de $6,3 \times 10^{5} \mathrm{~m}^{2}$. A altura de maré média local é da ordem de $0,8 \mathrm{~m}$, variando entre $0,4 \mathrm{e}$ $1,2 \mathrm{~m}$ durante períodos de quadratura e sizígia, respectivamente (Schettini, 2002). Utilizando a estimativa de vazão de $0,2 \mathrm{~m}^{3} \cdot \mathrm{s}^{-1}$, a razão de fluxo será 0,02 para maré média, ou, a troca estimada de água entre o Saco da Fazenda e o baixo estuário do rio ItajaíAçú é duas ordens de magnitude maior (100 vezes mais) do que o volume de água doce aportado através da drenagem local. A variação da razão de fluxo para variações sinodicais ficam em $\sim 0,04$ e $\sim 0,01$ para condições de quadratura e sizígia, respectivamente.

A taxa de renovação pode ser principalmente atribuída pela troca diária através do prisma de maré, ou a razão entre o prisma de maré com o volume médio do ambiente. Em casos em que o ambiente não apresente mudanças significativas da área devido a emersão durante a baixa mar, a taxa de renovação pode ser simplificada pela razão entre a altura da maré pela profundidade média do sistema, $\bar{p}$ :

$k=\frac{P_{M}}{V}=\frac{A h}{A \bar{p}}=\frac{h}{\bar{p}}$

Considerando a profundidade média de $1,5 \mathrm{~m}$, a taxa de renovação é de 0,53 para altura de maré media, variando entre 0,27 e 0,80 para alturas de maré de quadratura e sizígia, respectivamente. Os tempos de meia vida calculados pela Eq. 4 ficam em 1,3 dia para altura de maré media, 2,6 dias para maré de quadratura e 0,8 dia para maré de sizígia. Estes valores não devem ser considerados absolutos, mas como referência temporal, ou uma leitura tal como "o tempo de renovação das águas do Saco da Fazenda é de poucos dias". Para termos de escala e comparação, ao invés de utilizar o volume do prisma utilizar o numerador da Eq. 5, o volume de água proveniente da drenagem durante um ciclo de maré semidiurno, a taxa de renovação será de 0,01 , e o tempo de meia vida da ordem de 70 dias. Isto enfatiza a importância da troca de água com o estuário através do prisma de maré.

\section{Relação Entre o Saco da Fazenda e Estuário do Rio Itajaí-Açú \\ Uma vez que o tempo de residência no Saco da} Fazenda é de poucos dias, conclui-se que as condições hidrológicas nele estão em íntima associação com as condições hidrológicas do estuário do rio Itajaí-Açú. A salinidade média do saco é de 8 . Este valor foi obtido da média de 37 levantamentos realizados mensalmente no período de junho de 2000 até julho de 2003 (Figura 4), em seis estações distribuídas espacialmente. Estas medições foram realizadas durante o monitoramento ambiental da dragagem realizada no SF. Praticamente não há variação espacial da salinidade média, indicando a homogeinidade espacial desta variável. Considerando o trecho de estuário conexo ao saco, da desembocadura até os primeiros três quilômetros, e a camada superficial do estuário, dos primeiros 2,5 metros de coluna de água, obteremos que a salinidade média é de 7 . O valor da salinidade média do estuário foi obtido através da média de 47 campanhas realizadas semanalmente ao longo do estuário durante os anos de 1998 e 1999 para o monitoramento ambiental do Porto de Itajaí.

A consideração de utilizar os primeiros $2,5 \mathrm{~m}$ de coluna de água do estuário foi baseada pela soma da profundidade média do SF, $1,5 \mathrm{~m}$, e a altura de maré média regional de $0,8 \mathrm{~m}$, resultando em $2,3 \mathrm{~m}$, ou arredondamento para 2,5 m. A água nesta camada de coluna de água do estuário é a que está mais diretamente associada com as trocas com o SF. O estuário do rio Itajaí-Açú apresenta profundidade média da ordem de $7 \mathrm{~m}$ e elevado grau de estratificação vertical da salinidade (Schettini, 2002). Na maior parte do tempo é observada uma variação de dezenas de unidades de salinidade entre a camada de superfície e o fundo. Daí a importância de se escalar adequadamente a camada de troca disponível no estuário para intercambiar volume com o SF.

A salinidade média muito similar entre o SF e o estuário, mesmo que obtida em dois períodos amostrais distintos, indica que o tempo de renovação das águas do estuário é uma variável que passa também a ser importante na questão da qualidade do saco. Diferentemente do que ocorre no SF, o tempo de renovação do estuário é determinado principalmente pela descarga fluvial. A renovação de água do SF ocorre pela entrada e saída de volume através da mesma abertura, e é esperado que as parcelas de água mais afastadas da abertura levem um tempo maior para serem trocadas. 
Assim torna-se mais adequado a utilização do princípio de tempo de meia vida apresentado acima. No estuário há duas aberturas, uma a montante por onde entra o influxo unidirectional para jusante de água doce, o que força a renovação das águas pelo princípio de conservação de massa; e outra a jusante, a barra, onde há troca bidirecional em função das marés. Neste caso é mais adequado empregar o tempo de reposição de água doce no sistema, ou, o tempo necessário para que todo o volume de água doce seja reposto pela descarga fluvial (Dyer, 1997; Miranda et al. 2002). O volume de água doce contido na bacia estuarina $V_{D}$ é determinado pela relação

$V_{D}=V\left(1-\frac{S}{S_{0}}\right)$

onde este $V$ se refere ao volume da bacia estuarina, $S$ é a salinidade média no estuário e $S_{0}$ é a salinidade média de referência na zona costeira. A salinidade média no estuário obtida também a partir do monitoramento ambiental do Porto de Itajaí durante 1998 e 1999 é de 12,5. A salinidade média na região costeira obtida durante quatorze cruzeiros oceanográficos realizados mensalmente entre novembro de 2002 e dezembro de 2003 é de 32,6 (Schettini et al., 2005). Embora o estuário do rio Itajaí-Açú apresente um extensão total de $70 \mathrm{~km}$, a zona de mistura do estuário compreende a porção do baixo e médio estuário, que se estende da desembocadura até onde desemboca o rio Luís Alves, cerca de $35 \mathrm{~km}$ da desembocadura (Schettini et al. 2006). O estuário apresenta largura regular de cerca de $200 \mathrm{~m}$, e a profundidade média é cerca de $7 \mathrm{~m}$. Assim, o volume na região de interação entre água doce e salgada é da ordem de $49 \times 10^{6} \mathrm{~m}^{3}$, e aplicando a Eq. 7 obtemos que $\mathrm{V}_{\mathrm{D}} \sim 30 \times 10^{6} \mathrm{~m}^{3}$.

O tempo de reposição de água doce $T_{R}$ é obtido pela razão entre o volume de água doce na bacia estuarina pela taxa de entrada de água doce, a descarga fluvial ou vazão, $Q_{F}$

$$
T_{R}=\frac{V_{D}}{Q_{F}}
$$

A vazão do rio Itajaí-Açú é monitorada diariamente na estação fluviométrica de Indaial desde 1929. Esta estação está a noventa quilômetros da desembocadura do estuário, e representa a vazão de uma drenagem de 11110 km² (Agência Nacional de Águas - ANA). Esta estação é a mais a jusante no rio que não apresenta os efeitos oscilatórios periódicos de maré. A vazão média para os anos de 1998 e 1999 foi de $373 \mathrm{~m}^{3} \cdot \mathrm{s}^{-1}$ na estação fluviométria de Indaial. Adotando uma aproximação linear em relação a área total da bacia de drenagem do rio Itajaí-Açu, de $15.500 \mathrm{~km}^{2}$, a vazão corrigida será de $\sim 520 \mathrm{~m}^{3} . \mathrm{s}^{-1}$. Aplicando a Eq. 8, obtemos que o tempo de reposição de água doce no estuário será de 16 horas. Novamente faz se aqui a ressalva da aproximação, e a leitura do resultado é que o tempo de reposição é da ordem de meio dia.

Este resultado de tempo de reposição de água doce converge com os cálculos feitos por Zaleski \& Schettini (2003) para determinação do tempo de trânsito das águas do estuário do rio Itajaí-Açú. A diferença conceitual entre tempo de reposição e tempo de trânsito é que o último é uma estimativa do tempo gasto para uma parcela de água que entrou no estuário sair, calculado através do Teorema Hidrográfico de Knudsen (Miranda et al. 2002). Este teorema é baseado no princípio de conservação de massa de água e sal em um sistema altamente estratificado, pressupondo que a dinâmica do sistema é primeiramente regida pela vazão. Estas condições são verificadas para o estuário do rio Itajaí-Açu, principalmente em condições de vazão moderada para alta (Schettini, 2002). Para um período de vazão da ordem de $300 \mathrm{~m}^{3} \cdot \mathrm{s}^{-1}$, Zaleski \& Schettini (2003) encontraram que o tempo de trânsito para a camada superior do estuário foi de 13 horas, e para a camada inferior foi de 51 horas. A camada superior do estuário é dominada pela advecção fluvial, o que induz a renovação mais rápida do volume por conservação do volume, e.g., o volume aportado pela vazão fluvial flui pela camada de superfície. A camada de fundo, mais salina, apesar de apresentar deslocamento para montante e jusante em função das correntes de maré, apresenta velocidade residual pequena, e assim, maior tempo de trânsito.

A implicação de um tempo de reposição e tempo de trânsito próximos do período de maré semi-diurno, de 12 horas e 25 minutos, é que a cada ciclo de maré haverá água nova para entrar no SF. O fato de que o sistema apresenta profundidade média de $1,5 \mathrm{~m}$ garante que a água trocada será da camada superficial do estuário. Adicionalmente, também diminui a relação entre o volume do saco e o prisma de maré. Assim, a conjugação destes fatores garante uma qualidade de água razoável mesmo recebendo elevadas cargas de poluentes através dos cursos de água que aportam no saco (e.g. Rörig et al., 2006).

\section{Variação Temporal da Salinidade}

Foi apresentado nas seções anteriores que o SF apresenta um tempo de renovação do volume de água relativamente curto, e que o volume é trocado sempre por água nova da camada superior do estuário do rio Itajaí-Açú a cada ciclo de maré. Contudo, a água nova proveniente da bacia de drenagem do rio Itajaí-Açú não 
necessariamente é um ponto positivo para a qualidade ambiental do SF. A bacia hidrográfica do rio Itajaí-Açú apresenta pobre estado de conservação, sendo que o curso do rio recebe aporte de efluentes agro-pecuários, domésticos e industriais (Rörig, 2005; Pereira Fo., 2006). Embora em níveis ordens de grandeza menores do que os observados na drenagem direta do SF (e.g., Rörig et al., 2006), as águas fluviais são em geral mais ricas em nutrientes, sedimentos em suspensão, e potencialmente em contaminantes.

As condições restritas da hidrodinâmica do SF fazem dele uma bacia de decantação, e assim, a quantidade de sedimentos que entra é potencialmente maior do que a quantidade que sai a cada ciclo de maré. A fração do material que decanta retém junto contaminantes em potencial. Contudo, na maior parte do tempo a vazão fluvial do rio Itajaí-Açu é baixa. Como indicado pela salinidade média da camada superficial do estuário conexo ao SF, há uma fração significativa de água costeira neste trecho do estuário, o que apresenta um efeito diluidor sobre potenciais contaminantes (Schettini et al. 2006). A proximidade da abertura do SF da desembocadura do estuário sugere que nestes períodos a água que entra no saco durante os períodos de enchente de maré seja considerada também nova. Porém, as águas com maiores teores de salinidade, ou o equivalente menor fração de água doce, indicam que esta água nova apresenta qualidades ambientais superiores à água nova de origem fluvial.

A salinidade foi uma das variáveis monitoradas no SF no período entre junho de 2000 e julho de 2003, com o objetivo de acompanhar as condições ambientais durante a obra de dragagem de aprofundamento deste ambiente. Ao longo do monitoramento foram realizadas trinta e sete campanhas mensais quando foi medida a salinidade em seis pontos distribuídos espacialmente no saco. Durante os três anos de monitoramento foi possível realizar amostragens em diferentes condições de vazão do rio Itajaí-Açú (Fig. 4). A vazão média do rio Itajaí-Açú durante os anos de 2000 até 2003 foi de 282 $\mathrm{m}^{3} \cdot \mathrm{s}^{-1}$ na estação fluviométrica de Indaial, ou de 393
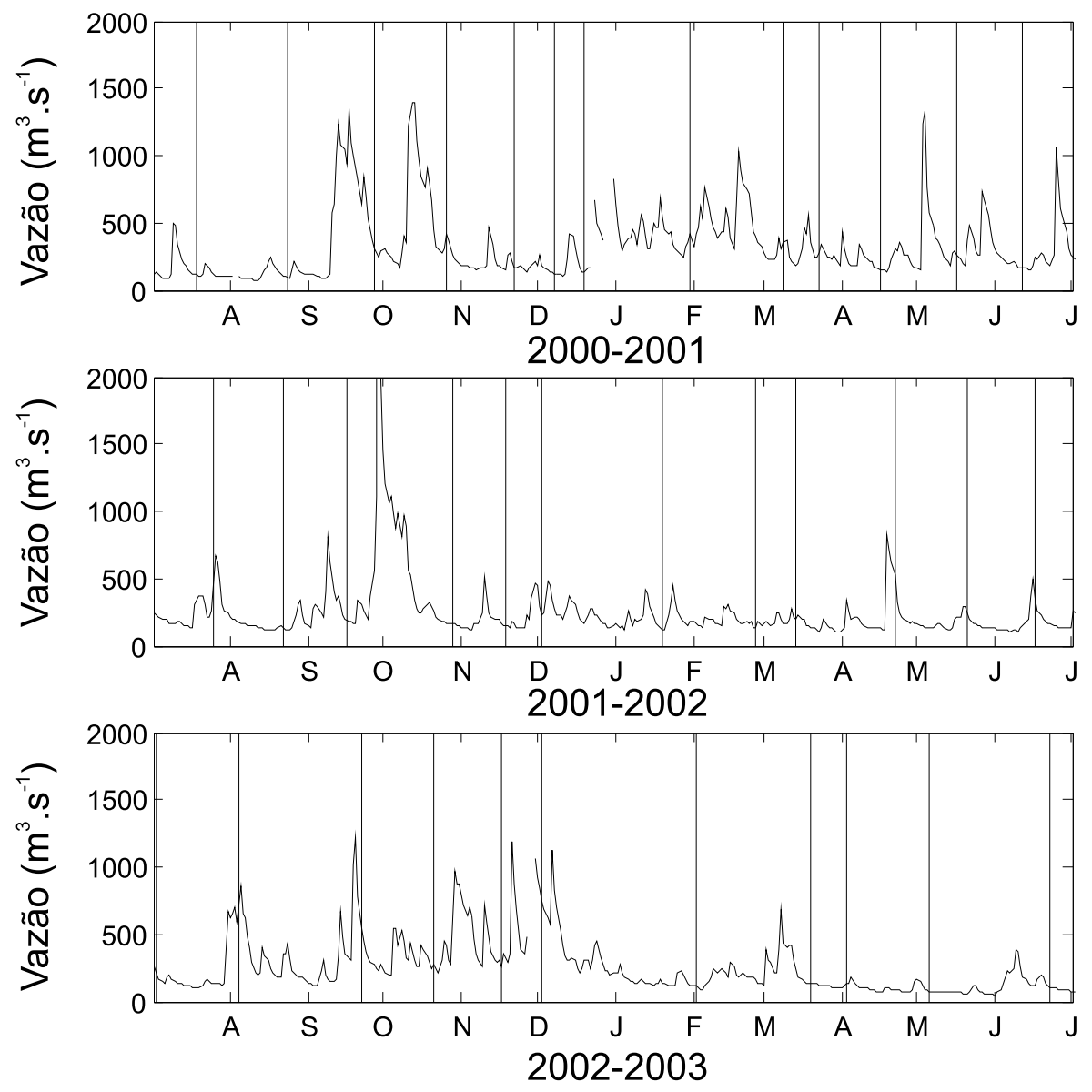

Figura 4 - Vazão diária do rio Itajaí-Açú medida na estação fluviométrica de Indaial para o período de julho de 2000 até junho de 2003 . As linhas verticais ao longo dos gráficos indicam os dias em que foram realizadas campanhas de coleta de dados no Saco da Fazenda. 
$\mathrm{m}^{3} \cdot \mathrm{s}^{-1}$ corrigido para toda a bacia. Os valores mínimos e máximos observados neste período foram de 55 (77) e $3474(4850) \mathrm{m}^{3} \cdot \mathrm{s}^{-1}$, respectivamente. O primeiro ano de monitoramento (julho de 2000 a junho de 2001) apresentou condições médias de maior vazão durante todo o tempo, com vazões elevadas se estendo por vários dias em diversas ocasiões.

A salinidade média temporal do SF foi de 8 , apresentando razoável variabilidade temporal (Fig. 5). O maior valor de salinidade observado foi de 25 na primeira campanha de monitoramento realizada em junho de 2000. Somente em outras duas ocasiões a salinidade foi maior que 15, em março de 2002 e fevereiro de 2003. A mínima salinidade média espacial do saco foi de 0,5, observada em setembro de 2002. Também ocorreram outras ocasiões de salinidade baixa, como em setembro de 2000, agosto e dezembro de 2002. Não é possível distinguir um padrão sazonal da variação da salinidade, porém sempre os menores valores foram observados no segundo semestre dos anos.

A relação entre a salinidade média do SF com a descarga fluvial sinótica do rio Itajaí-Açú na estação fluviométrica de Indaial é apresentada na Figura 6. É observada uma tendência de que quanto maior for a descarga fluvial, menor será a salinidade média do saco. A variação da salinidade em função da vazão foi mais bem ajustada através de uma relação de decaimento potencial dado por

$$
\text { Salinidade }=532,1 \text { Vazão }^{-0,805}
$$

cujo coeficiente de determinação $r^{2}=0,56$. Houve apenas duas observações de salinidade para vazões elevadas, acima de $700 \mathrm{~m}^{3} \cdot \mathrm{s}^{-1}$. A maior parte das observações foram em condições de baixa vazão $(<$ $\left.150 \mathrm{~m}^{3} . \mathrm{s}^{-1}\right)$, e vazões intermediárias. Uma vez que a relação está sendo aplicada sobre dados brutos, sem distinção se as coletas foram realizadas em condições de maré de quadratura ou sizígia, ou ainda entre preamar e baixamar, ocorre um grande espalhamento de pontos nesta faixa de vazão.

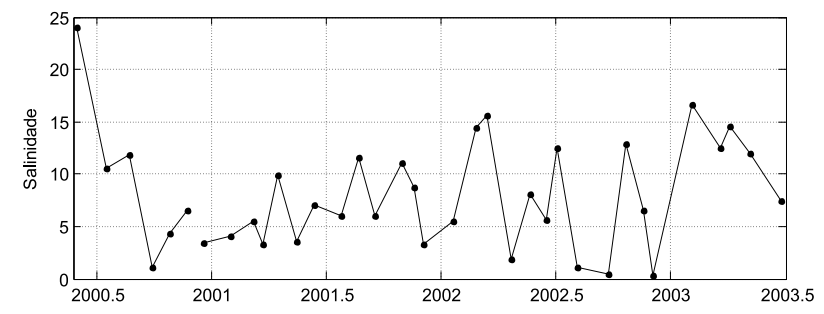

Figura 5 - Variação temporal da salinidade média no Saco da Fazenda durante o período do monitoramento ambiental da dragagem entre 2000 e 2003.
Quando a vazão do rio Itajaí-Açú está acima de 300-400 $\mathrm{m}^{3} \cdot \mathrm{s}^{-1}$, é estabelecido um regime dinâmico fortemente estratificado, onde os primeiros metros de coluna de água são dominados por água doce. Como esta é a camada de interação entre o estuário e o saco, e visto que o tempo de troca é bastante curto, é esperada uma rápida diminuição da salinidade nestes períodos. Contudo, os picos de descarga elevada costumam durar horas a poucos dias, o que diminui o potencial de explicação da variância da salinidade pela vazão. Em condições de vazão média para baixa, a camada superficial do baixo estuário nunca fica dominada por água doce, sempre havendo maiores teores de sal. Adicionalmente, nestes períodos de baixa vazão a fase da maré influenciará significativamente a salinidade média da camada superior do estuário. Haverá uma forte modulação da salinidade em função da fase de maré, se enchente ou vazante. Esta modulação será tão maior quanto for a altura de maré.

\section{SUMÁRIO}

O Saco da Fazenda pode ser considerado em termos hidrológicos como uma lagoa costeira do tipo vazada;

A sua qualidade da água esta intimamente relacionada com as trocas com o baixo estuário do rio Itajaí-Açu;

O tempo de renovação da água é função básica do prisma de maré, sendo da ordem de poucos dias;

A salinidade média responde razoavelmente bem às variações sinóticas da vazão do rio Itajaí-Açu.

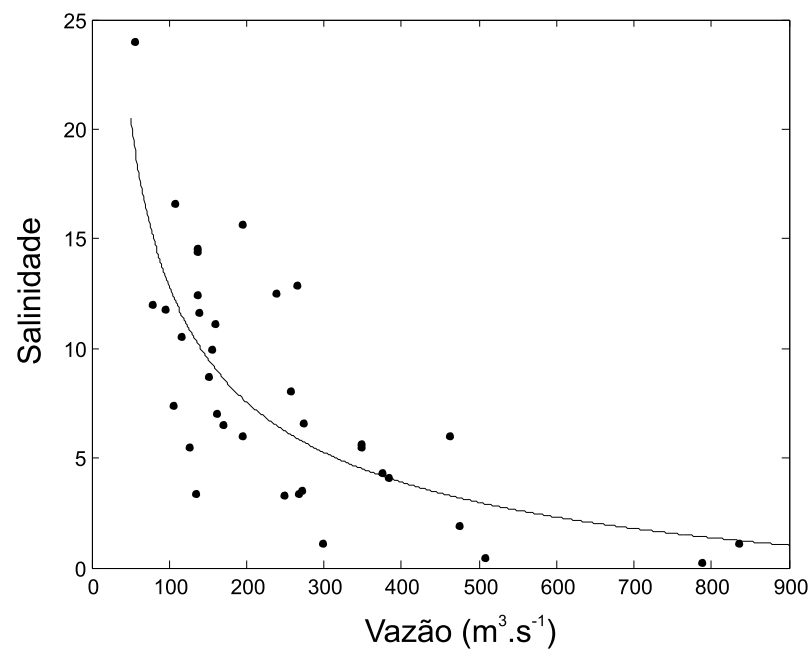

Figura 6 - Relação da salinidade em função da vazão fluvial do rio Itajaí-Açú em Indaial. Equação: Sal = 532,1 x Vazão ${ }^{-0,805}$, com r $^{2}=$ 0,56 . 


\section{AGRADECIMENTOS}

O autor agradece aos comentários e sugestões dos revisores. Bolsa Pq/CNPq-306217/2007-4.

\section{REFERÊNCIAS}

Barnes, H. 1980. Coastal lagoons. London, Cambridge University Press, 106p.

Cameron, W.N. \& Pritchard, D.W. 1963. Estuaries. In: Goldberg, E.D.; McCave, I.N.; O'Brien, J.J.; Steele, J.H. (eds.) The sea. V.2, New York, John Wiley \& Sons,:306-324.

Carmouze, J.P. 1992. The eutrophication of the Lagoon of Saquarema, Brazil. Science of Total Environment, 851-859.

Dyer, K.R. 1997. Estuaries: a physical introduction. 2nd Ed. New York, John Wiley \& Sons, 195p.

Emery, K.O. 1967. Estuaries and lagoons in relation to continental shelves. In: LAUFF, G.H. (ed.) Estuaries. Washington, American Association for the Advancement of Science, № 83, p9-11.

GAPLAN - Gabinete de Planejamento de Santa Catarina 1986 Atlas de Santa Catarina. Rio de Janeiro, Aerofoto Cruzeiro, 173pp.

Hansen, D.V. \& Rattray, M. 1966. New dimensions on estuarine classification. Limnology and Oceanography, 11:319-326.

Kjerfve, B. 1986. Comparative oceanography of coastal lagoons. In: WOLFE, D.A. (ed.) Estuarine Variability. New York, Academic Press, p63-81.

Kjerfve, B. 1994. Coastal lagoon processes. New York, Elsevier, 577p.

Kjerfve, B. \& Magill, K.E. 1989. Geographic and hydrographic characteristics of shallow coastal lagoons. Marine Geology, 88:187-199.

Kjerfve, B. \& Knoppers, B. 1991. Tidal choking in a coastal lagoon. In: PARKER, B. (ed.) Tidal Hydrodynamics. New York, John Wiley \& Sons, pp169-179.

Knoppers, B.; Kjerfve, B.; Carmouze, J.P. 1991. Trophic state and water turn-over time in six choked coastal lagoons in Brazil. Biogeochemistry, 14(2):149-166.

Lankford, R.R. 1977. Coastal lagoons of Mexico: their origin and classification. In: WILEY, M. (ed.) Estuarine processes. V.2, New York, Academic Press, p182-215.

Merino,M.; Czitrom,S.; Jordán,E.; Martin,P.; Thomé,P.; Moreno,O. 1990. Hydrology and rain flushing of the Nichupté Lagoon System, Cancún, México. Estuarine, Coastal and Shelf Science, 30:223-237.

Miranda, L.B.; Castro Fo., B.M.; Kjerfve, B. 2002. Princípios de oceanografia física de estuários. São Paulo, Edusp, 411p.
Moore, N.H. \& Slinn, D.J. 1984. The physical hydrology of a lagoon system on the Pacific coast of Mexico. Estuarine, Coastal and Shelf Science, 19:413-426.

Nichols, M.M. \& Biggs, R.B. 1985. Estuaries. In: Davis Jr., R.A. (ed.) Coastal sedimentary environments. New York, Springer Verlag, p77-187.

Pereira Fo., J. 2006. Dinâmica biogeoquímica do estuário do rio Itajaí-Açú São Carlos, UFSCar, Tese de Doutorado. 158pp.

Phleger, F.B. 1981. A review of some general features of coastal lagoons. UNESCO Technical Papers in Marine Science, 33:7-14.

Pritchard, D. 1961 Disposal of radioactive wastes in the ocean. Health Physics, 6:103-109.

Rörig, L.R. 2005. Usos múltiplos e qualidade das águas da bacia do baixo Itajaí-Açu/SC: elementos para um gerenciamento integrado. São Carlos, UFSCar, Tese de Doutorado, 295pp.

Rörig, L.R.; Tundisi, J.G.; Schettini, C.A.F.; Pereira Fo., J.; Menezes, J.T.; Almeida, T.C.M.; Urban, S.R.; Radetski, C.M.; Sperb, R.C.; Stramosk, C.A.; Macedo, R.S.; Casto-Silva, M.A.; Perez, J.A.A. 2006. From a water resource to a point pollution source: the daily journey of a coastal urban stream. Brazilian Journal of Biology, 67(4):631-637.

Schettini, C.A.F. 2002. Caracterização física do estuário do rio Itajaí-Açu. Revista Brasileira de Recursos Hídricos, 7(1):123-142.

Schettini, C.A.F.; Resgalla Jr., C.; Pereira Fo., J.; Silva, M.A.C.; Truccolo, E.C.; Rörig, L.R. 2005. Variabilidade temporal das características oceanográficas e ecológicas da região de influência fluvial do rio Itajaí-Açu. Brazilian Journal of Aquatic Science and Technology, 9(2):93-102.

Schettini, C.A.F.; Ricklefs, K.; Truccolo, E.C.; Golbig, V. 2006. Synoptic hydrography of an highly stratified estuary. Ocean Dynamics, 56(3-4):308-319.

Smith, N.P. 1988. The Laguna Madre of Texas: hydrography of a hypersaline lagoon. IN: KJERFVE, B. (ED.) Hydrodinamics of estuaries, Boca Raton, CRC Press, p 31-40.

Vargas, B.M. 1983. Evolução histório-morfológica do estuário do Rio Itajaí-açu e sua implicação no Porto de Itajaí - SC. Rio de Janeiro, INPH, Relatório 139/ 83, 138p.

Zaleski, A.R. \& Schettini, C.A.F. 2003. Estimação do tempo de trânsito das águas no estuário do rio ItajaíAçu. Notas Técnicas da Facimar, 7:63-72.

Zimmerman, J.T.F. 1981. The flushing of well-mixed tidal lagoons and its seasonal fluctuation. UNESCO Technical Papers in Marine Science, 33:15-26. 